\title{
DFT study of new organic materials based on PEDOT and 4-[2-(2-N, N-dihydroxy amino thiophene) vinyl] benzanamine
}

\section{Côme Damien Désiré Mveme}

University of Maroua: Universite de Maroua

Fridolin Tchangnwa Nya ( $\square$ nyafridolin@yahoo.fr )

Universite de Maroua https://orcid.org/0000-0002-8882-6987

Geh Wilson Ejuh

University of Bamenda

Alhadji Malloum

University of Maroua: Universite de Maroua

Jeanet Conradie

University of the Free State - Bloemfontein Campus: University of the Free State

Jean Marie Bienvenu Ndjaka

University of Yaounde I: Universite de Yaounde I

\section{Research Article}

Keywords: DFT, PEDOT and PEDOT derivatives, Optoelectronic properties, nonlinear optical properties, thermodynamic properties

Posted Date: April 20th, 2021

DOl: https://doi.org/10.21203/rs.3.rs-261912/v1

License: (9) This work is licensed under a Creative Commons Attribution 4.0 International License.

Read Full License 
DFT study of new organic materials based on PEDOT and 4-[2-(2-N, N-dihydroxy amino thiophene) vinyl] benzanamine

\author{
Côme Damien Désiré Mveme ${ }^{1}$, Fridolin Tchangnwa Nya ${ }^{1^{*}}$, Geh Wilson Ejuh ${ }^{2,3}$, Alhadji \\ Malloum $^{1,4}$, Jeanet Conradie ${ }^{4}$, Jean Marie Bienvenu Ndjaka ${ }^{5}$ \\ ${ }^{1}$ University of Maroua, Faculty of Science, Department of Physics, P.O. Box 814 Maroua, \\ Cameroon. Materials Science Laboratory. \\ ${ }^{2}$ University of Bamenda, National Higher Polytechnic Institute, Department of Electrical and \\ Electronic Engineering, P. O. Box 39 Bambili, Cameroon. \\ ${ }^{3}$ University of Dschang, IUT-FV Bandjoun, Department of General and Scientific Studies, P.O. Box \\ 134, Bandjoun, Cameroon. \\ ${ }^{4}$ Department of Chemistry, University of the Free State, PO Box 339, Bloemfontein, 9300, South \\ Africa \\ ${ }^{5}$ University of Yaoundé I, Faculty of Science, Department of Physics, P.O. Box 812 Yaounde, \\ Cameroun. \\ ${ }^{*}$ Corresponding author: \\ E-mail address: nyafridolin@yahoo.fr
}

\begin{abstract}
:
In the present study, we theoretically determine the optoelectronic, electronic, nonlinear optical (NLO) and thermodynamic properties of new materials from the conjugated polymer poly $(3,4-$ ethylenedioxythiophene) (PEDOT) doped with halogens (Fluorine and Chlorine) combined with the organic semiconductor 4-[2-(2-N, N-dihydroxy amino thiophene) vinyl] benzamine (DATVB). The molecular geometry of the ground state, the optoelectronics and electronics parameters have been calculated by combining the $6-311++\mathrm{G}(\mathrm{d}, \mathrm{p})$ basis set with functionals of the density functional theory (DFT). The functionals B3LYP and the CAM-B3LYP have been used for NLO parameters. The energy gaps obtains for all the compounds are less than $3.0 \mathrm{eV}$. These results clearly show that PEDOT and its derivatives can be considerated as good semiconductors. They can be tested for use in the manufacture of organic solar cells (OSC) and organic light emitting diodes (OLED). The first order hyperpolarisabilities of these PEDOT hybrid compounds are much higher than those of the reference compound for NLO applications, namely para-nitroaniline (p-NA), which opens up a new field of application of PEDOT in NLO devices. The thermodynamic parameters such as the zero point vibrational energy $(\mathrm{ZPVE})$, the enthalpy $(\mathrm{H})$, the heat capacity at constant volume $(\mathrm{Cv})$, the entropy $(S)$ and the free energy $(G)$ have been calculated and reported herein.
\end{abstract}

Keywords: DFT, PEDOT and PEDOT derivatives, Optoelectronic properties, nonlinear optical properties, thermodynamic properties 


\section{Introduction}

In 1997, some researchers discovered that the polyacetylene polymer shows a high conductivity in its doped state [1-2]. This discovery has openned the door to a new universe dedicated to exploration of organic semiconductors in order to reduce inorganic polymers utilization on all electronic devices.

Since this pioneering work of 1997 until today, many interesting polymer have been explored and studied to identify possible applications of them. In this regard, at the industrial scale, some conjugated polymer appears to be very promising for applications in "molecular engineering". One of them is poly (3, 4-ethylenedioxythiophene) (PEDOT, Scheme 1a) which is a low band gap polymer with a high conductivity and good thermal and chemical resistance proven [3].

PEDOT exhibits great stability in its doped state [4], with conductive properties that are truly constant over time: this is its major advantage.

All the same, like all other molecule PEDOT presents some inconvenient and one of them are his insolubility: PEDOT is an insoluble polymer. But his polymerisation in combination with water dispersible polyelectrolyte such as poly (4-styrenesulfonate) (PSS) leads to soluble compound called PEDOT/PSS.

PEDOT doped with PSS ( PEDOT/PSS) has been so much studied and it's now well characterized by many works which let us know that PEDOT/PSS has good transparency in visible spectrum and good film-forming properties[4]. It is used like hole transport layer in light emitting devices [5]. In photovoltaic devices [6], photodiodes [7], field effect transistors (OFET) [8] to quote only those, PEDOT doped with PSS is largely used.

Despite this wide range of application areas for PEDOT/PSS, several works are ongoing to study the fundamental electronic properties and the nature of the excited states in neutral and doped conjugated materials. Studies have shown that, in order to characterize a polymer, it must be interesting to study its monomeric state because it is pure and the results obtained are more reliable, to validate them with long monomers [9].

In recent years, PEDOT / PSS has been incorporated into many organic devices to facilitate charge transfer and improve their electrical conductivities [10-12]. Even though many applications of PEDOT / PSS have been studied by experimental methods [13-16], there has not been much research concerning the establishment of hybrid materials of PEDOT with other organic semiconductor molecules. PEDOT hybrids that are particularly stable, less polluting, with a range of optical properties with electronic forbidden bands varying over the entire visible spectrum, may be useful for the applications mentioned above.

In 2017, Tchangnwa Nya et al [17], carried out a theoretical study of the molecular 4- [2- (2-N, $\mathrm{N}$-dihydroxy amino thiophene) vinyl] benzenamine (DATVB, scheme 1b) using the density functional theory method. They determined the energy gap, dipole moment and first order polarizability of DATVB. They obtained different interesting values: $2.16 \mathrm{eV}$ for the energy gap $($ Egap $=2.16 \mathrm{eV}) ; 2.88$ Debye for the dipole moment $(\mu=2.88$ Debye $) ; 412.27 \times 10^{-33}$ esu for the first order molecular hyperpolarizability $\left(\beta_{\mathrm{mol}}=412.27 \times 10^{-33} \mathrm{esu}\right)$. In view of these results, they concluded that molecular DATVB was predisposed for applications in electronics, optoelectronics and nonlinear optics.

In this article, we thus propose new stable PEDOT based hybrid materials that can be synthesized from the experientially known PEDOT polymer and the theoretically proposed, DATVB alloy, 
forming PEDOT / DATVB, see Scheme 1c. We also present the properties of the halogen doped PEDOT and PEDOT / DATVB (halogens F and Cl to form PEDOT-F, PEDOT-Cl, PEDOT-F / DATVB and PEDOT-Cl / DATVB respectively).

The properties of the resulting PEDOT / DATVB, PEDOT-F, PEDOT-Cl, PEDOT-F / DATVB, PEDOT-Cl / DATVB alloy can replace PEDOT in its various applications mentioned above. After optimizing a model PEDOT / DATVB polymer (Scheme $1 \mathrm{c}$ with $\mathrm{n}=3$ ), we determine the optoelectronic and electronic transport properties as well as the nonlinear optical and thermodynamic properties of these new materials. We will carry out these investigations using DFT.

(a)

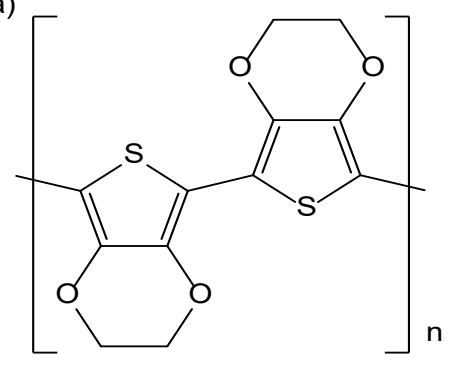

(b)

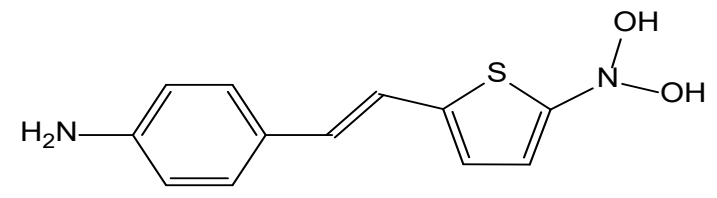

(c)<smiles>Cc1ccc(N)cc1</smiles><smiles>CCON(O)O</smiles><smiles></smiles>

Scheme 1. Structure of (a) the PEDOT polymer, (b) the DATVB molecule and (c) the proposed PEDOT / DATVB alloy. In this study PEDOT / DATVB is modeled with $n=3$.

\section{Theoretical framework and computational details 1.1.Theoretical framework}

The mathematical relations used to calculate the optoelectronic properties, nonlinear optics, electronic transport and chemical parameters are as follows:

- For optoelectronic properties:

The electric displacement field $\mathrm{D}$ is given by

$$
D=\varepsilon_{0} E+P=\varepsilon_{0} \varepsilon_{r} E=\varepsilon_{0}\left(1+\chi_{e}\right) E=\varepsilon E
$$

where the density of electrical polarization $P$ is given by

$$
P=\varepsilon_{0} \chi_{e} E=\left(\varepsilon_{r}-1\right) E \varepsilon_{0}
$$

with $\mathrm{E}=$ external electric field and $\varepsilon_{0}$ and $\varepsilon_{r}$ the permittivity of vacuum and relative permittivity respectively.

The refractive index $n$ is defined by the relation: 


$$
n=\sqrt{1+\chi_{e}}
$$

with $\chi_{e}=$ electric susceptibility.

- In the non-linear domain, the dipole moment $\mu$ is governed by the formula :

$$
\mu=\alpha E+\beta E^{2}+\gamma E^{3}+\cdots
$$

Where $\alpha, \beta$ and $\gamma$ are respectively the polarizability, the first and second order dipole hyperpolarizability terms.

$$
\begin{gathered}
\alpha=\frac{1}{3}\left(\alpha_{x x}+\alpha_{y y}+\alpha_{z z}\right) \\
\beta=\sqrt{\beta_{x}^{2}+\beta_{y}^{2}+\beta_{z}^{2}} \\
\text { with } \\
\beta_{x}=\beta_{x x x}+\beta_{x y y}+\beta_{x z z} \\
\beta_{y}=\beta_{y y y}+\beta_{y x x}+\beta_{y z z} \\
\beta_{z}=\beta_{z z z}+\beta_{z x x}+\beta_{z y y}
\end{gathered}
$$

The anisotropy, $\Delta \alpha$, electric field, $\mathrm{E}$, polarization $\mathrm{P}$ and volume $\mathrm{V}$ are calculated by

$$
\begin{aligned}
& \Delta \alpha=\frac{1}{2}\left[\left(\alpha_{x x}-\alpha_{y y}\right)^{2}+\left(\alpha_{y y}-\alpha_{z z}\right)^{2}+\left(\alpha_{z z}-\alpha_{x x}\right)^{2}+6\left(\alpha_{x y}^{2}+\alpha_{y z}^{2}+\alpha_{z x}^{2}\right)\right]^{1 / 2} \\
& \mathrm{E}=\mu / \alpha \\
& \mathrm{P}=\mu / \mathrm{V} \\
& \mathrm{V}=\mathrm{R}^{3}(\mathrm{R}=\text { radius })
\end{aligned}
$$

The dipole moment $\mu$ can be expressed as:

$$
\mu=\sqrt{\mu_{x}^{2}+\mu_{y}^{2}+\mu_{z}^{2}}
$$

- For the properties of electronic transport and quantum chemical parameters:

Parameters such as gap energy ( $\left.E_{\text {gap }}\right)$, ionization potential (IP), electronic affinity (EA), overall hardness $(\eta)$, flexibility $(\zeta)$, electronegativity $(\chi)$, chemical potential $(\mu c)$, and the electrophilicity index $(\omega)$ are given by the following formulas involving the energies of the highest occupied and lowest unoccupied molecular orbitals ( $\mathrm{E}_{\text {Hомо }}$ and $\left.\mathrm{E}_{\mathrm{LUMO}}\right)$ :

$$
\begin{aligned}
& \mathrm{E}_{\text {gap }}=\mathrm{E}_{\text {LUMO }}-\mathrm{E}_{\text {HOMO }} \\
& \mathrm{IP}=-\mathrm{E}_{\text {HOMO }} \\
& \mathrm{EA}=-\mathrm{E}_{\text {LUMO }} \\
& \mu c=-\left(\frac{\text { IP+EA }}{2}\right) \\
& \chi=-\mu c \\
& \eta=\frac{\text { IP-EA }}{2} \\
& \zeta=\frac{1}{\eta} \\
& \omega=\frac{\mu_{c}^{2}}{2 \eta}
\end{aligned}
$$

These mathematical relations above are used by other authors in previous works [17-28] 


\subsection{Computational details}

The optimized structures of the compounds, the corresponding harmonic energy, vibrational frequencies and the quantum chemical properties were obtained using DFT (B3LYP), which is a cost-effective method of including electronic correlations, associated to the $6-311++\mathrm{G}(\mathrm{d}, \mathrm{p})$ basis set as implemented in the Gaussian 16 software [29]. The functional B3LYP is a relatively inexpensive and precise method for predicting molecular structures, energies and frequencies [19, $24,30,31]$. A new density functional Coulomb-attenuated hybrid exchange-correlation functional (CAM-B3LYP) has been developed and it is suitable to predict the molecular NLO properties of a large system [32]. It has been shown that this functional provides good results for electronic excitation energies [33-36], first [37], second hyperpolarizabilities [38] and even electric fieldinduced second harmonic generation [39]. The calculations of dipole moment, polarizability and hyperpolarizability are also performed using CAM-B3LYP with the same basis set. Figure 1 gives the B3LYP/6-311++G (d, p) optimized structures of the different compounds namely a reduced PEDOT model (P1, n=3 in Scheme 1a), PEDOT-F (P2), PEDOT-Cl (P3), PEDOT / DATVB (P4), PEDOT-F / DATVB (P5) and PEDOT-Cl / DATVB (P6).

The formation of the materials $\mathrm{P} 2, \mathrm{P} 3, \mathrm{P} 4, \mathrm{P} 5$ and $\mathrm{P} 6$ was evaluated by the following reactions:

$$
\begin{aligned}
& \mathrm{PEDOT}+\mathrm{F}_{2} \rightarrow \text { PEDOT-F }+\mathrm{H}_{2} \\
& \mathrm{PEDOT}+\mathrm{Cl}_{2} \rightarrow \mathrm{PEDOT}-\mathrm{Cl}+\mathrm{H}_{2} \\
& \mathrm{PEDOT}+\mathrm{DATVB} \rightarrow \mathrm{PEDOT} / \mathrm{DATVB}+\mathrm{H}_{2} \\
& \mathrm{PEDOT}-\mathrm{F}+\mathrm{DATVB} \rightarrow \mathrm{PEDOT}-\mathrm{F} / \mathrm{DATVB}+\mathrm{HF} \\
& \mathrm{PEDOT}-\mathrm{Cl}+\mathrm{DATVB} \rightarrow \mathrm{PEDOT}-\mathrm{Cl} / \mathrm{DATVB}+\mathrm{HCl}
\end{aligned}
$$

The formation of these materials is energetically favorable if the reaction energies $\left(E_{r}\right)$ of their formation are negative [40-42]. Likewise, these reactions are spontaneous even if the reaction Gibbs free energies $\left(G_{r}\right)$ is also negative. The reaction energies of $(\mathrm{P} 4)$ formation as example, is calculated using the equation:

$$
E_{r}^{P_{4}}=\mathrm{E}(\mathrm{PEDOT} / \mathrm{DATVB})+\mathrm{E}\left(H_{2}\right)-\mathrm{E}(\mathrm{PEDOT})-\mathrm{E}(\mathrm{DATVB})
$$

Where $\mathrm{E}(\mathrm{PEDOT} / \mathrm{DATVB}), \mathrm{E}(\mathrm{PEDOT}), \mathrm{E}(\mathrm{DATVB})$ and $\mathrm{E}\left(\mathrm{H}_{2}\right)$ are the total electronic energies of the PEDOT/DATVB, PEDOT, DATVB and $H_{2}$ respectively.

We calculate $\left(G_{r}\right)$ in the same way.

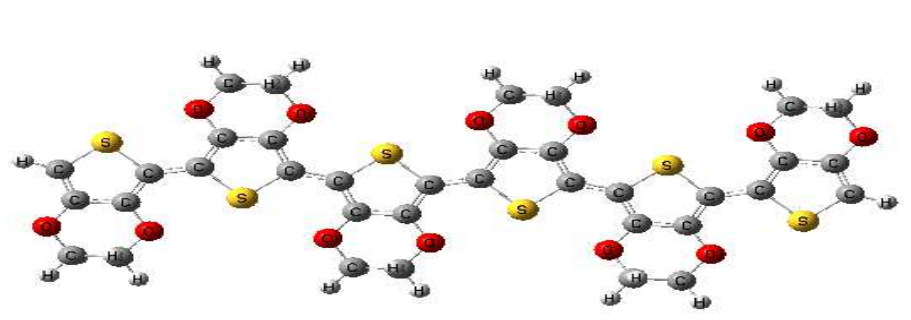

P1) PEDOT

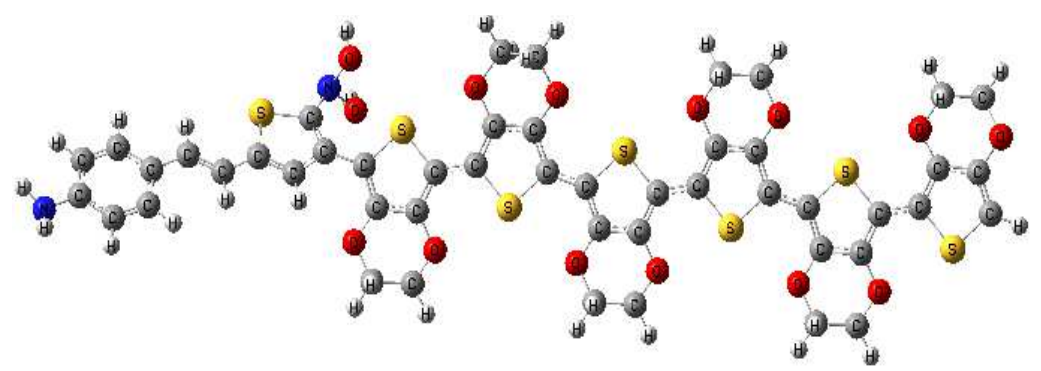

P4) PEDOT/DATVB 


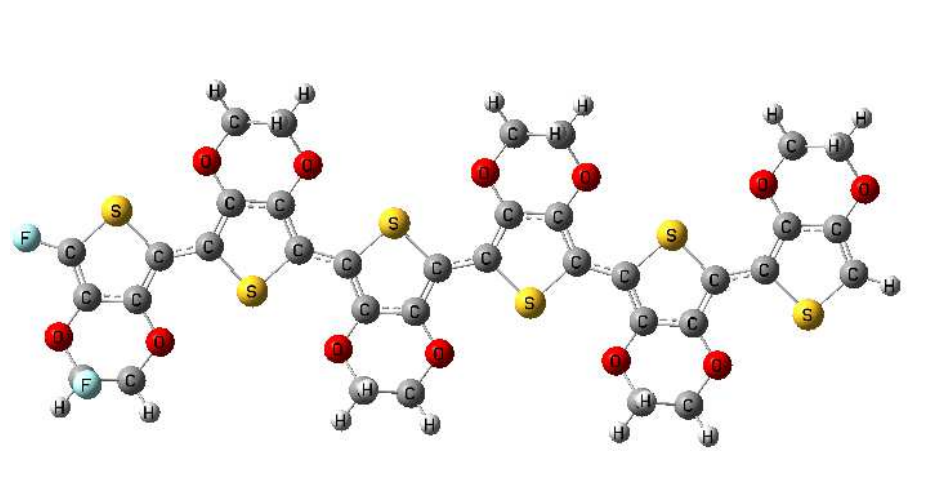

P2) PEDOT-F

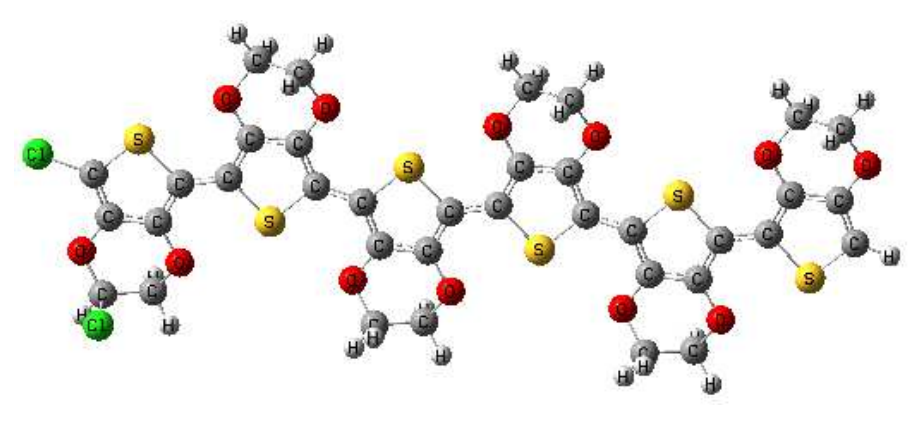

P3) PEDOT-Cl

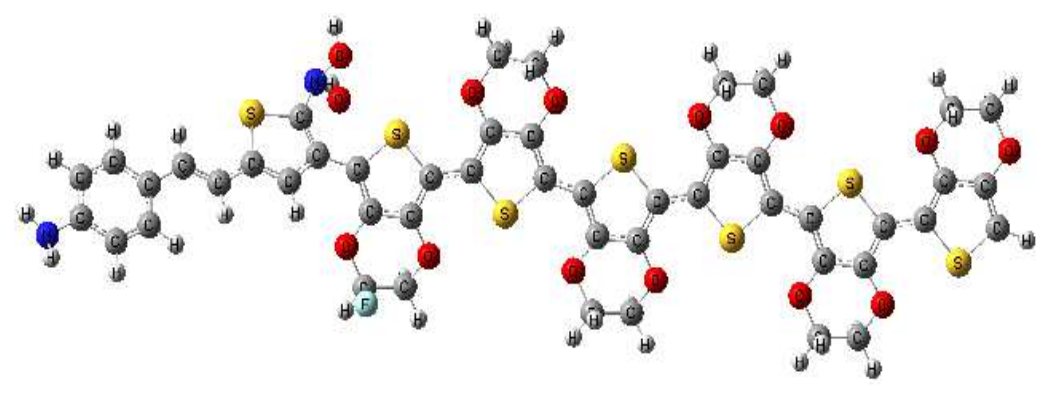

P5) PEDOT-F/DATVB

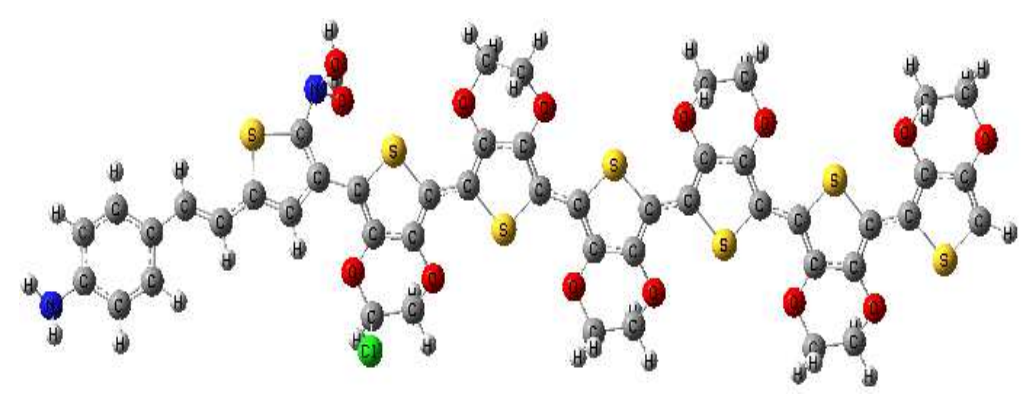

P6) PEDOT-Cl/DATVB

Figure 1: Different optimized molecular systems studied and the complex numbers used (P1 - P6).

\section{Results and discussions}

\subsection{Analysis reaction energies}

The structural stability of the modeled molecular structures can be described with computed total electronic energies [40]. The stability of materials PEDOT-F, PEDOT-Cl, PEDOT/DATVB, PEDOT-F/DATVB and PEDOT-Cl/DATVB are evaluated by calculating the reaction energies of reactions (19) - (23) above and the reaction Gibbs free energies. Table 1 presents the reaction energies $E_{r}$ and reaction Gibbs Free energies $G_{r}$ of the newly proposed compounds P2, P3, P4, P5 and P6. As shown in Table 1, P2, P3, P5 and P6 have negative reaction energies and reaction Gibbs free energies values, suggesting that the synthesis of this material are energetically favorable and spontaneous without energy supply. P4 has positive reaction energy and reaction Gibbs free energy values, suggesting that the synthesis of this material are favorable with an energy supply. Compound P4 may exist but in its halogenated form, it exhibits excellent properties in its stable state. These results leave us optimistic and we believe that our different model systems are stable and can be synthesized from an experimental point of view.

Table 1: Calculated reaction energies, $E_{r}$ of the synthesis reactions of materials $\mathrm{P} 2, \mathrm{P} 3, \mathrm{P} 4, \mathrm{P} 5$ and P6. 


\begin{tabular}{lccccc}
\hline & P2 & P3 & P4 & P5 & P6 \\
\hline$E_{r}($ in $\mathrm{kcal} / \mathrm{mol})$ & -85.08 & -6.28 & 14.82 & -17.36 & -10.60 \\
$G_{r}($ in $\mathrm{kcal} / \mathrm{mol})$ & -86.62 & -8.59 & 14.83 & -15.01 & -9.59 \\
\hline
\end{tabular}

\subsection{Geometric study of PEDOT and PEDOT/DATVB derivatives}

The geometric parameters of the B3LYP/6-311++G $(d, p)$ optimized structures of the molecules are recorded in Table 2. Values obtained for PEDOT with six ethylenedioxythiophene units $(\mathrm{n}=3$ in Scheme 1 (a)) in this study, are in good agreement with reported periodic quantum-chemical calculation [43-45], as well as experimental crystallographic values for BEDOT ( $\mathrm{n}=1$ in Scheme 1 (a)) [46]. The DFT method used in this study, namely modeling PEDOT with six ethylenedioxythiophene units $(\mathrm{n}=3$ in Scheme 1 (a)) using B3LYP/6-311++G $(\mathrm{d}, \mathrm{p})$, thus gives a good representation of the geometry of PEDOT.

We note the interatomic distances and the valence angles are almost identical when comparing the PEDOT molecule to the PEDOT / DATVB molecule. The investigated systems have been well optimized without any imaginary frequencies. Therefore, they can be synthesized from the experimental point of view.

Table 2: Theoretical and experimental values (from this work and literature) of interatomic distances $(\AA)$ and angles $\left({ }^{\circ}\right)$ of the molecules reported in this study. The indicated values of the inner rings are given.

\begin{tabular}{lllllc}
\hline $\begin{array}{l}\text { Geometric } \\
\text { parameters }\end{array}$ & $\begin{array}{l}\text { PEDOT } \\
\text { /B3LYP }\end{array}$ & $\begin{array}{l}\text { PEDOT } \\
\text { /PW91 }^{\mathrm{b}}\end{array}$ & $\begin{array}{l}\text { PEDOT } \\
\text { /BLYP }^{\mathrm{c}}\end{array}$ & $\begin{array}{l}\text { BEDOT } \\
\text { (exp }^{\mathrm{d}}\end{array}$ & $\begin{array}{c}\text { PEDOT/DATVB } \\
\text { /B3LYP }^{\text {B }}\end{array}$ \\
\hline Reference & $\mathrm{TW}^{\mathrm{a}}$ & {$[43]$} & {$[45]$} & {$[46]$} & TW $^{\mathrm{a}}$ \\
\hline $\mathrm{R}(\mathrm{C}-\mathrm{S})$ & 1.736 & & 1.772 & 1.732 & 1.736 \\
$\mathrm{R}(\mathrm{C}=\mathrm{C})$ & 1.380 & 1.38 & 1.392 & 1.373 & 1.377 \\
$\mathrm{R}(\mathrm{C}-\mathrm{C})^{\mathrm{e}}$ & 1.519 & 1.40 & 1.523 & 1.483 & 1.519 \\
$\mathrm{R}(\mathrm{C}-\mathrm{C})^{\mathrm{f}}$ & 1.438 & 1.41 & 1.431 & 1.442 & 1.460 \\
$\mathrm{R}(\mathrm{C}-\mathrm{O})^{\mathrm{g}}$ & 1.369 & & 1.391 & 1.369 & 1.371 \\
$\mathrm{~A}(\mathrm{C}-\mathrm{S}-\mathrm{C})$ & 92.4 & 92.7 & 93.43 & 92.4 & 92.8 \\
$\mathrm{~A}(\mathrm{C}-\mathrm{O}-\mathrm{C})$ & 112.6 & & 111.8 & 111.4 & 112.7 \\
$\mathrm{~A}(\mathrm{C}-\mathrm{C}-\mathrm{C})$ & 128.4 & 128.7 & 128.8 & 127.5 & 128.2 \\
\hline
\end{tabular}

${ }^{\mathrm{a}} \mathrm{TW}=$ this work

${ }^{\mathrm{b}}$ periodic quantum-chemical calculations with PW91 from reference [43].

${ }^{\mathrm{c}}$ periodic quantum-chemical calculations with BLYP from reference [45].

${ }^{\mathrm{d}}$ experimental for $\mathrm{n}=1$ in Scheme 1 (a) CSD reference number QEYQAM

$\mathrm{e}$ in ethylenedioxy ring

${ }^{\mathrm{f}}$ between thiophene rings

${ }^{\mathrm{g}} \mathrm{C}$ (thiophene)-O

\subsection{Optoelectronic properties}

Organic materials with conjugated polymers chemically exhibit $\pi$ double bonds, which give them good electronic transport properties and good optical properties. Optoelectronics is based on the 
quantum mechanical effects of light on electronic materials, in particular semiconductors, sometimes in the presence of electric fields. In this work, the optoelectronic parameters such as the electric field $(E)$, the polarization density $(\mathrm{P})$, the electric susceptibility $\left(\chi_{e}\right)$, the dielectric constant $(\varepsilon)$, the refractive index $(\mathrm{n})$, and the electric displacement vector (D) were evaluated using the functional B3LYP and the basis set 6-311 ++ G (d, p) while applying the mathematical relations given above. The results obtained are reported in Table 3 below.

In our work, we have observed that mean electric field (E) of the doped PEDOT with DATVB increases and lead to an augmentation of the density of polarization $(\mathrm{P})$ in comparison with the nondoped PEDOT.

In the same order, the doping of PEDOT by DATVB leads to an average increase of opticals and electric properties such as electric susceptibility $\left(\chi_{e}\right)$, refraction indice $(n)$, dielectric constant $(\varepsilon$ and amplitude of vector deplacement (D). Theses augmentations can be explained by the large average polarisability obtained. It has been reported that PEDOT and PEDOT/PSS are recognized to have very good optoelectronics properties such as conductivity and refraction indice [43].

By performing an analysis of parameters, values for the non-doped polymer (P4) with doped polymer (P5, P6) who are polymers doped with halogens, we observe that optoelectronic properties of theses ones grow significantly due to the doping. This could be due to the presence of halogens within these molecules as they have the same physical and chemical properties.

From the above, in agreement with the literature, PEDOT has good optoelectronic properties [26, 43, 47-48] but its doping with the DATVB molecule on the one hand and halogenated PEDOT / DATVB on the other hand improves its properties which further makes this molecule very attractive. These results thus suggest that the P2, P3, P4, P5 and P6 derived from PEDOT can also be validly used in optoelectronic devices, in particular in the manufacture of organic solar cells (OSC) and organic light-emitting diodes (OLED) [49-52].

Table 3: Electric field (E), electric polarization density (P), electrical susceptibility $\left(\chi_{\mathrm{e}}\right)$, dielectric constant $(\varepsilon)$, refractive index $(\mathrm{n})$, electric displacement $(\mathrm{D})$, radius $(\mathrm{R})$ and volume (V) of P1, P2, P3, P4, P5 and P6 obtained at the B3LYP/6-311++G (d, p) level of theory.

\begin{tabular}{lllllll}
\hline \multicolumn{1}{c}{ Parameters } & \multicolumn{1}{c}{$\mathrm{P} 1$} & \multicolumn{1}{c}{$\mathrm{P} 2$} & $\mathrm{P} 3$ & $\mathrm{P} 4$ & \multicolumn{1}{c}{$\mathrm{P} 5$} & \multicolumn{1}{c}{$\mathrm{P} 6$} \\
\hline $\mathrm{E}\left(\mathrm{Vm}^{-1}\right) 10^{8}$ & 0.024 & 7.53 & 7.92 & 4.91 & 4.85 & 5.03 \\
$\mathrm{P}\left(\mathrm{Cm}^{-2}\right) 10^{-2}$ & 0.009 & 3.095 & 3.55 & 2.31 & 2.27 & 2.33 \\
$\chi_{\mathrm{e}}$ & 4.48 & 4.63 & 5.05 & 5.31 & 5.29 & 5.22 \\
$\varepsilon 10^{-11}$ & 4.86 & 4.99 & 5.36 & 5.59 & 5.57 & 5.51 \\
$\mathrm{n}$ & 2.34 & 2.37 & 2.46 & 2.51 & 2.50 & 2.49 \\
$\mathrm{D} 10^{-2}$ & 0.011 & 3.76 & 4.25 & 2.75 & 2.70 & 2.77 \\
$\mathrm{R}(\mathrm{m}) 10^{-10}$ & 7.13 & 7.05 & 6.97 & 7.58 & 7.58 & 7.64 \\
$\mathrm{~V}\left(\mathrm{~m}^{3}\right) 10^{-30}$ & 362.46 & 350.40 & 338.61 & 435.52 & 435.52 & 445.94 \\
\hline
\end{tabular}

\subsection{Electronics properties and energy analysis}


The HOMO (Highest Occupied Molecular Orbital) and LUMO (Lowest Unoccupied Molecular Orbital) concepts are fundamental for the understanding of electronic behaviour of a given molecule. In fact, with theses ones we can study the chemical stability and reactivity of the system.

When the difference energy between HOMO-LUMO is high, it indicates that we are in presence of a hard molecule, otherwise, if the difference is minor, we have an soft molecule [25]. Molecular stability and hardness are inversely linked. The molecule with the small HOMO-LUMO gaps are more reactive. By energy difference between energy of neutral compound and those of the compound oxidised and reduced respectively, we determine: the ionisation potential (IP) and the electronic affinity (EA). In table 4, we have reported for every systems the quantum chemical parameters calculated such as: Highest occupied molecular orbital energy (Еномо), Lowest unoccupied molecular orbital (ELUmo), Energy gap (Egap), Electronegativity $(\chi)$, Chemical potential $\left(\mu_{\mathrm{c}}\right)$, overall hardness $(\eta)$, softness $(\zeta)$ and electrophilicity index $(\omega)$.

The exploitation of this table reveals that: ionization potential (IP) and electronegativity $(\chi)$ undergo a significant augmentation generally though we pass from the non-doped PEDOT to the doped PEDOT/DATVB with its halogenated forms. This observation is still valid for other parameters as: electrophilicity index $(\omega)$, and overall hardness $(\eta)$.

This result explains the high mobility of electrons and the holes within these molecules (as found in the previous section) which considerably improves their electronic properties. In addition, the values of the B3LYP/6-311++G $(\mathrm{d}, \mathrm{p})$ calculated gap energy PEDOT $\left(\mathrm{E}_{\text {gap }}=2.45 \mathrm{eV}\right)$ are in close agreement with reported calculated values of the PEDOT using periodic DFT with $\mathrm{n}=2(1.8 \mathrm{eV})$ [53], the experimental band gap of PEDOT of $1.5 \mathrm{eV}$ [8] and the experimental band gap PEDOT / PSS $(1.5 \mathrm{eV})$ [54]. The B3LYP/6-311++G $(\mathrm{d}, \mathrm{p})$ calculated band gap of our different molecular structures modeled P2 $\left(E_{\text {gap }}=2.44 \mathrm{eV}\right), \mathrm{P} 3\left(\mathrm{E}_{\text {gap }}=2.42 \mathrm{eV}\right), \mathrm{P} 4\left(\mathrm{E}_{\text {gap }}=2.36 \mathrm{eV}\right)$ P5 $\left(\mathrm{E}_{\text {gap }}=2.37\right.$ $\mathrm{eV})$ and $\mathrm{P} 6\left(\mathrm{E}_{\mathrm{gap}}=2.37 \mathrm{eV}\right)$ are in close agreement with the above mentioned reported values of the PEDOT [54] and PEDOT / PSS. With regard to these low gap energies obtained for P2, P3, P4, P5 and P6, we can propose that the investigated systems have very good electrical conductivities compared to PEDOT pristine, because electrical conductivity $\sigma$ and $\mathrm{E}_{\text {gap }}$ are closely related by the relation:

$$
\sigma \propto \exp \left(-\frac{E_{g a p}}{\mathrm{kT}}\right)
$$

Where $\mathrm{k}$ is the Boltzmann constant [55-56]. Other calculated values published of the HOMOLUMO gap in the PEDOT using different DFT method, range from $0.7 \mathrm{eV}$ to $2.7 \mathrm{eV}[7,43,57,58$ 61]. The experimental conductivity of PEDOT is as high as $550 \mathrm{~S} / \mathrm{cm}$ [62].

HOMO and LUMO orbitals are orbitals which produce information on density of electronics states (DOS), at the same time the DOS are used for the determination of the molecule part most actively implicated in a phenomenon of energy electronics transfer by localizing the gap energy of the semiconductors as we have observed on our different modeled systems. Figure 2 gives the diagram of the HOMO and LUMO of our modelled systems where we easily observe the difference in the character of the HOMO and the LUMO.

At the level of the $\pi$ bonds, we have observed that the HOMO and the LUMO extend over the entire backbone of the PEDOT, allowing the movement of electrons throughout the molecule. The P4 - P6 LUMOs also extend into the DATVB ligand.

Moreover, in accordance with the work of the authors present in the literature [28], it is common knowledge that the highest and lowest unoccupied molecular orbitals (respectively HOMO and 
LUMO), are the most important parameters allowing to know how the molecule interacts in the transfer of charges.

In view of the results obtained in our systems presented above, we propose that these new materials resulting from doping, would be good candidates for applications in electronic devices because they exhibit a very interesting electronic and optoelectronic behaviour when we compare our values to values of other molecules found in the literature with the same methods and basis set $[43,63]$.

Table 4: $\mathrm{E}_{\mathrm{LUMO}}, \mathrm{E}_{\text {Hомо }}, \mathrm{E}_{\text {gap }}$, chemical potential $(\mu \mathrm{c})$, electronegativity $(\chi)$, absolute hardness $(\eta)$, softness $(\zeta)$, ionization potential (IP), Electronic affinity (EA) and electrophilic index ( $\omega)$ of the molecules obtained at the B3LYP/6-311++G $(d, p)$ level of theory

\begin{tabular}{lllllll}
\hline Parameters & P1 & P2 & P3 & P4 & P5 & P6 \\
\hline $\mathrm{E}_{\text {Lumo }}(\mathrm{eV})$ & -1.76 & -1.85 & -1.89 & -1.77 & -1.81 & -1.82 \\
$\mathrm{E}_{\text {Hомо }}(\mathrm{eV})$ & -4.21 & -4.29 & -4.32 & -4.13 & -4.18 & -4.19 \\
$\mathrm{E}_{\text {gap }}(\mathrm{eV})$ & 2.45 & 2.44 & 2.42 & 2.36 & 2.37 & 2.37 \\
$\mu c(\mathrm{eV})$ & -2.99 & -3.07 & -3.10 & -2.95 & -2.99 & -3.01 \\
$\chi(\mathrm{eV})$ & 2.99 & 3.07 & 3.10 & 2.95 & 2.99 & 3.01 \\
$\eta(\mathrm{eV})$ & 1.23 & 1.22 & 1.21 & 1.18 & 1.19 & 1.19 \\
$\zeta(1 / \mathrm{eV})$ & 0.81 & 0.81 & 0.82 & 0.85 & 0.84 & 0.84 \\
$\mathrm{IP}(\mathrm{eV})$ & 4.21 & 4.29 & 4.32 & 4.13 & 4.18 & 4.19 \\
EA $(\mathrm{eV})$ & 1.76 & 1.85 & 1.89 & 1.77 & 1.81 & 1.82 \\
$\omega(\mathrm{eV})$ & 3.64 & 3.86 & 3.97 & 3.69 & 3.75 & 3.80 \\
\hline
\end{tabular}

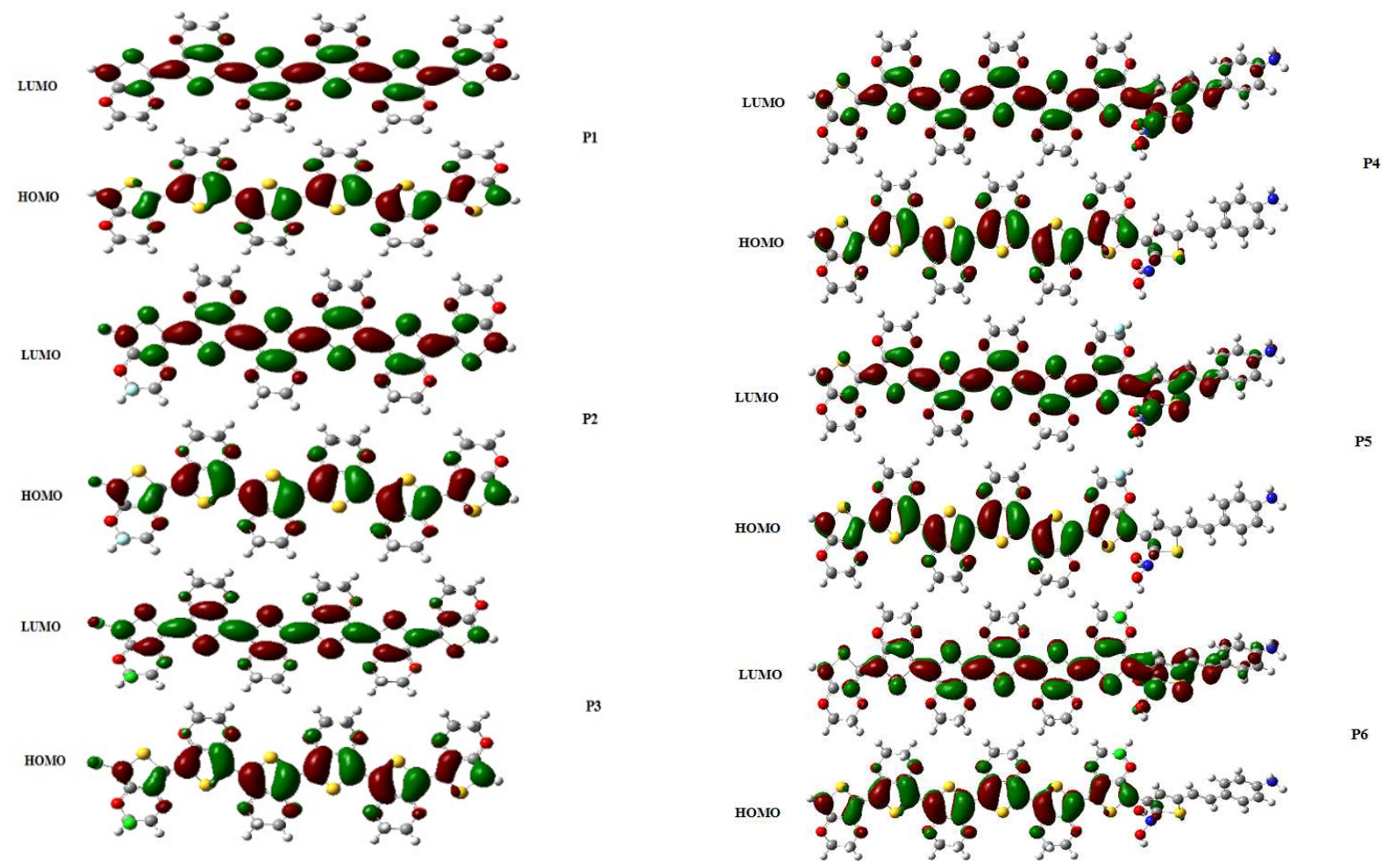


Figure 2: Diagram of the LUMO and HOMO molecular orbitals of the P1, P2, P3, P4, P5and P6 structures obtained at the B3LYP/6-311++G $(d, p)$ level of theory.

\subsection{Linear and non-linear properties}

Nonlinear optics correspond to optical phenomena involving fields intense electrics of the order of the interatomic field. The classical treatment of light-matter interaction supposes the implication of weak electric fields giving place in a linear relationship between the electric field of light and the properties of the atomic system of the material. A very intense beam of light can generate a nonresponse linear from the middle. To fully understand the properties of P1 - P6, the linear and nonlinear optical (NLO), parameters such as dipole moment $(\mu)$, mean polarizability $(\alpha)$, anisotropy $(\Delta \alpha)$, first order hyperpolarizability $\left(\beta_{\mathrm{mol}}\right)$ were calculated in this work at the B3LYP and CAMB3LYP with the same basis set while applying the relations (4-10) mentioned above. The values obtained are reported in Table $5 \mathrm{a}$ and Table $5 \mathrm{~b}$.

It can be seen in Table 5a and Table 5b that all the values of the dipole moments for P2, P3, P4, P5 and P6 are greater than zero, indicating that these materials are polar. Moreover when we analyse the six components of the asymmetric tensor of polarizability as well as the three components of the tensor of hyperpolarizability of the first order we note that only the components $\alpha_{\mathrm{xx}}$ and $\beta_{\mathrm{z}}$ have large values. We can therefore conclude that $\alpha_{x x}$ and $\beta_{z}$ are mainly responsible of the linear and the non-linear character of these molecules, respectively. We note an excellent electronic distribution in the molecule P2, P3, P4, P5 and P6 because of their extremely high values (see Table 5a and table $5 b)$ of the average polarizability $\langle\alpha\rangle$.

Para-nitroaniline (p-NA), is an organic prototype molecule for the study of the nonlinear optical parameters of organic materials push-pull, the experimental value of its first order hyperpolarisability $\left(\beta \mathrm{mol}\right.$, expérimental) in esu is $\beta_{\mathrm{mol}}$, experimental $=(9261 \pm 380) \times 10^{-33} \mathrm{esu}[64]$. In this new work we have calculated the first order polarisability of para-nitroaniline (p-NA), by DFT study with CAM-B3LYP, we have obtained theoretical value for the first order polarisability ( $\beta \mathrm{mol}$, calculated) (esu) $\beta_{\mathrm{mol} \text { calcul }}=14261,32 \times 10^{-33}$ esu.

We can see that our values are much higher than that of this reference molecule, which suggests that our studied systems have very good NLO properties. In addition, we note that only P2, P3, P4, P5 and P6 have higher values of $\beta_{\text {mol }}$ (see Table 5) than those of p-NA. We can therefore conclude that these new materials resulting from doping of PEDOT in addition of being very good semiconductors, open another field of application of this molecule of nonlinear optics devises and as photonic materials [65-71].

Table 5a: Dipolar moment $(\mu)$, polarisability $(\alpha)$, anisotropy $(\Delta \alpha)$, first order hyperpolarisability $\left(\beta_{\text {mol }}\right)$ of the molecule obtained at the B3LYP/6-311++G(d,p) level of theory.

\begin{tabular}{lccccccc}
\hline Parameters & P1 & P2 & P3 & P4 & P5 & P6 & p-Na \\
\hline$\mu$ (Debye) & 0.01 & 3.25 & 3.60 & 3.02 & 2.97 & 3.11 & 7.48 \\
$\alpha_{\mathrm{xx}}$ & 179.43 & 1625.06 & 1721.78 & 270.49 & 1816.34 & 1823.90 & 154.71 \\
$\alpha_{\mathrm{xy}}$ & -74.43 & -73.06 & -73.16 & -113.11 & -747.55 & -741.58 & 0.0008 \\
$\alpha_{\mathrm{yy}}$ & 88.18 & 678.88 & 699.97 & 134.06 & 899.33 & 911.39 & 99.83 \\
$\alpha_{\mathrm{xz}}$ & 43.85 & -1.45 & -8.84 & 63.61 & 422.26 & 417.31 & -0.36
\end{tabular}




\begin{tabular}{lccccccc}
$\alpha_{\mathrm{yz}}$ & -24.66 & 0.34 & 9.36 & -33.76 & -235.21 & -247.20 & -0.0002 \\
$\alpha_{\mathrm{zz}}$ & 120.88 & 313.37 & 338.11 & 148.42 & 998.93 & 1017.93 & 51.07 \\
$\alpha(\mathrm{esu}) 10^{-24}$ & 129.51 & 129.29 & 136.33 & 184.34 & 183.49 & 185.40 & 15.09 \\
$\Delta \alpha(\mathrm{esu}) 10^{-24}$ & 123.77 & 123.58 & 130.94 & 188.17 & 185.60 & 184.57 & 9.41 \\
$\beta_{\mathrm{x}}$ & -63.02 & 8290.31 & 16830.39 & 6598.95 & 16926.34 & 18782.91 & 1650.45 \\
$\beta_{\mathrm{y}}$ & -87.13 & -524.28 & -1131.82 & -1156.55 & -5479.39 & -6383.29 & -0.01 \\
$\beta_{\mathrm{z}}$ & 19.73 & 254.81 & -37.93 & -2620.03 & 669.47 & 1592.83 & -31.51 \\
$\beta_{\mathrm{mol}}(\mathrm{esu}) 10^{-33}$ & 944.53 & 71798.35 & 145730.68 & 62146.92 & 153811.26 & 171936.66 & 14261.32 \\
\hline
\end{tabular}

Table 5b: Dipolar moment $(\mu)$, average polarisability $(\alpha)$, anisotropy $(\Delta \alpha)$, first oder hyperpolarisability $\left(\beta_{m o l}\right)$ of the molecule obtained at the CAM-B3LYP/6-311++G(d,p) level of theory.

\begin{tabular}{lccccccc}
\hline Parameters & P1 & P2 & P3 & P4 & P5 & P6 & $p-N a$ \\
\hline$\mu$ (Debye) & 0.01 & 3.07 & 3.21 & 2.96 & 3.21 & 3.28 & 7.48 \\
$\alpha_{\mathrm{xx}}$ & 1247.04 & -1244.41 & 1313.61 & 1812.31 & 1802.29 & 1809.82 & 143.49 \\
$\alpha_{\mathrm{xy}}$ & 5.32 & 1.04 & -8.52 & 21.56 & 17.93 & 16.37 & 0.003 \\
$\alpha_{\mathrm{yy}}$ & 650.27 & 648.79 & 668.83 & 797.61 & 795.21 & 810.10 & 98.20 \\
$\alpha_{\mathrm{xz}}$ & -1.60 & 5.41 & -6.66 & 22.31 & 22.27 & 23.69 & -0.33 \\
$\alpha_{\mathrm{yz}}$ & 0.05 & 5.88 & -6.89 & 1.15 & -1.09 & 0.29 & -0.14 \\
$\alpha_{\mathrm{zz}}$ & 307.79 & 307.54 & 331.07 & 461.89 & 466.89 & 481.91 & 50.41 \\
$\alpha(\mathrm{esu}) 10^{-24}$ & 108.93 & 108.71 & 114.28 & 151.74 & 151.38 & 153.23 & 15.09 \\
$\Delta \alpha(\mathrm{esu}) 10^{-24}$ & 86.28 & 86.07 & 90.63 & 127.73 & 126.41 & 125.64 & 8.44 \\
$\beta_{\mathrm{x}}$ & -1.46 & -2378.58 & 5402.28 & -3132.99 & 303.13 & 714.52 & -1360.15 \\
$\beta_{\mathrm{y}}$ & 9.79 & 17.01 & -65.22 & -1684.27 & -1869.31 & -1788.52 & -0.001 \\
$\beta_{\mathrm{z}}$ & 45.32 & -183.55 & -77.60 & -1318.04 & -1778.94 & -1686.50 & 22.96 \\
$\beta_{\mathrm{mol}}$ (esu)10 & 400.81 & 20610.95 & 46680.19 & 32772.12 & 22446.99 & 22116.71 & 14261.41 \\
\hline
\end{tabular}

\subsection{Thermodynamic properties}

The thermodynamic properties of the structures of P1, P2, P3, P4, P5 and P6, are reported in Table 6 referenced below. With regard to the observations made in this Table 6 , one can note that the values of the parameters ZPVE, $\mathrm{H}, \mathrm{CV}$ and $\mathrm{S}$ vary significantly by addition of the semiconductor DATVB and of fluorine and chlorine heteroatoms within the structure of the PEDOT. We observe furthermore that the values of enthalpy $\mathrm{H}$ and entropy $\mathrm{S}$ for doped compounds are higher than PEDOT pristine.

Table 6: Thermodynamic properties of studied compound Obtained at the B3LYP/6-311++G (d, p) level of theory at constant temperature and pressure. 


\begin{tabular}{lrrrrrr}
\hline \multicolumn{1}{c}{ Parameters } & \multicolumn{1}{c}{ P1 } & \multicolumn{1}{c}{ P2 } & \multicolumn{1}{c}{ P3 } & \multicolumn{1}{c}{ P4 } & \multicolumn{1}{c}{ P5 } & \multicolumn{1}{c}{ P6 } \\
\hline Eelec (a.u) & -4679.86 & -4878.39 & -5599.11 & -5801.40 & -5900.68 & -6261.03 \\
ZPVE (Kcal/Mol) & 357.88 & 348.01 & 346.17 & 483.66 & 478.79 & 477.79 \\
E0 (a.u) & -4679.29 & -4877.84 & -5598.55 & -5800.63 & -5899.92 & -6260.27 \\
E(a.u) & -4679.25 & -4877.79 & -5598.51 & -5800.58 & -5899.86 & -6260.21 \\
H(a.u) & -4679.25 & -4877.79 & -5598.50 & -5800.57 & -5899.85 & -6260.20 \\
G(a.u) & -4679.38 & -4877.93 & -5598.64 & -5800.75 & -5900.03 & -6260.38 \\
Ethermal(KCal/Mol) & 387.15 & 378.42 & 377.04 & 523.81 & 519.41 & 518.65 \\
Cv(Cal/Mol-Kelvin) & 178.64 & 184.00 & 185.75 & 243.25 & 245.63 & 246.71 \\
S (Cal/Mol-Kelvin) & 282.73 & 292.19 & 297.11 & 370.27 & 374.505 & 377.13 \\
\hline
\end{tabular}

- $E_{\text {elec }}=$ total electronic energy without zero point correction

- $\mathrm{ZPVE}=$ zero-point vibrational energy

- Sum of electronic and zero-point Energies $\mathrm{E}_{0}=\mathrm{E}_{\text {elec }}+\mathrm{ZPE}$

- Sum of electronic and thermal Energies $\mathrm{E}=\mathrm{E}_{0}+\mathrm{E}_{\mathrm{vib}}+\mathrm{E}_{\text {rot }}+\mathrm{E}_{\text {trans }}$

- Sum of electronic and thermal Free Energies $\mathrm{G}=\mathrm{H}-\mathrm{TS}$

- E (Thermal): Contributions to the thermal energy correction

- $\mathrm{CV}=$ Constant volume molar heat capacity

- $\mathrm{S}=$ Entropy

\section{Conclusion}

Firstly, we theoretically investigated PEDOT, halogen doped PEDOT and a new material derived from the PEDOT conjugate with the organic semiconductor DATVB (PEDOT/DATVB). In addition, two new materials obtained by halogen doped PEDOT and DATVB, namely PEDOTF/DATVB and PEDOT-Cl/DATVB have also been investigated. The investigations have been performed at the B3LYP/6-311++G(d,p) and CAM-B3LYP levels of theory. The results obtained on the structural properties (interatomic distances and valence angles ) are in agreement with previous works, which shows that the basis set and the methods chosen are appropriate for the study of these new systems. We also specify that during the optimization of these systems no imaginary frequency (or negative frequency) was observed which further suggests that these new materials are stable and can therefore validly replace the marketed PEDOT. The calculation of the formation reaction energies and the formation Gibbs free energies shows that these systems are thermodynamically stable and spontaneous therefore, can be synthesized. The evaluated optoelectronic properties of these materials leads to the conclusion that these materials find their applications in the manufacture of photovoltaic solar cells and other photonic components. Likewise, the gap energies of these molecules are smaller as compared to the theoretical and experimental values of PEDOT given in the literature. This explains why these materials are very good semiconductors which can consequently replace PEDOT in its multiple tasks in electronics. The large values of first-order molecular hyperpolarizability $\left(\beta_{\mathrm{mol}}\right)$ of the studied systems further opens up another field of application of PEDOT doped with DATVB in nonlinear optics. The thermodynamic parameters evaluated also 
exhibit remarkable thermodynamic stability of these new materials. We report for the first time the results obtained from $\mathrm{B} 3 \mathrm{LYP} / 6-311++\mathrm{G}(\mathrm{d}, \mathrm{p})$ calculations on these new materials based on the organic conductive polymers PEDOT. Therefore the new materials investigated in this study, namely PEDOT-F, PEDOT-Cl, PEDOT / DATVB, PEDOT-F / DATVB and PEDOT-Cl / DATVB, are promising candidates for emerging technologies.

\section{Acknowledgement}

The authors are grateful to the Center for High Performance Computing (CHPC), South Africa, for granting them access to their clusters and computational resources. We would also like to thank the Central Research Fund of the University of the Free State.

Conflict of Interest: The authors declare that they have no conflict of interest.

Availability of data and materials: All data generated or analysed during this study are included in this published article.

Code availability: the Gaussian 16 software.

\section{Authors Contribution:}

Côme Damien Désiré Mveme: Conceptualization; investigation; methodology; formal analysis; writing-original draft.

Fridolin Tchangnwa Nya: Conceptualization; investigation; methodology; writing-review and editing; Supervision.

Geh Wilson Ejuh: Writing-review and editing.

Alhadji Malloum: Writing-review and editing.

Jeanet Conradie: Writing-review and editing.

Jean Marie Bienvenu Ndjaka: Writing-review and editing.

\section{References}

[1] H. Shirakawa, E. J. Louis, A. G. MacDiarmid, C. K. Chiang, and A. J. Heeger. J Chem Soc, Chem Com. 578-580, (1977).

[2] C. K. Chiang, C. R. Fincher, Jr., Y. W. Park, A. J. Heeger, H. Shirakawa, E. J. Louis, S. C. Gau, A. G. MacDiarmid, Phys Rev Lett 39(17), 1098-1101(1977).

[3] L. Groenendaal, F. Jonas, D. Freitag, H. Pielartzik, J.R.Reynolds, Adv. Mater. 12, 481 (2000).

[4] G. Heywang, F. Jonas, Adv. Mater. 4, 116 (1992).

[5] R.H. Friend,R.W. Gymer, A.B. Holmes, J.H. Burroughes,R.N. Marks, C. Taliani, D.D.C. Bradley, D.A. Dos Santos, J.L. Bredas, M. Lo“gdlund, W.R. Salaneck, Nature 397, 121 (1999). 
[6] M. Granstrom, K. Petritsch, A.C. Arias, A. Lux, M.R. Andersson, R.H. Friend, Nature 395, 257 (1998).

[7] A. Dkhissi, F. Louwet, L. Groenendaal, D. Eljonne, R. Lazzaroni, J.L. Bredas, Chem. Phys. Lett. 359, 466 (2002).

[8] Q. Pei, G. Zuccafrello, M. Ahlskog, O. Inganas, Polymer 35, 1347 (1994).

[9] G. Wegner, K. Mullen, Eds. VCH: Weinheim, Electronic Materials-The Oligomer Approach. (1998).

[10] R. Chen, K. Sun, Q. Zhang, Y. Zhou, M. Li, Y. Sun, Z. Wu, Y. Wu, X. Li, J. Xi, C. Ma, Y. Zhang, and J. Ouyang, IScience 12, 66 (2019).

[11] A. Dhanabalan, J. K. J. Van Duren, P. A. Van Hal, J. L. J. Van Dongen, and R. A. J. Janssen, Adv. Funtional Mater. 11, 255 (2001).

[12] H. Okuzaki, H. Suzuki, T. Ito J. Phys Chem B 113 (33), 11378-11383 (2009).

[13] J. Ouyang, ACS Appl. Mater. Interfaces 5, 13082 (2013).

[14] J. Y. Oh, M. Shin, J. B. Lee, J. H. Ahn, H. K. Baik, and U. Jeong, ACS Appl. Mater. Interfaces 6, 6954 (2014).

[15] N. Kim, S. Kee, S. H. Lee, B. H. Lee, Y. H. Kahng, Y. R. Jo, B. J. Kim, and K. Lee, Adv. Mater. 26, 2268 (2014).

[16] A. K. Sarker, J. Kim, B. H. Wee, H. J. Song, Y. Lee, J. D. Hong, and C. Lee, RSC Adv. 5, 52019 (2015).

[17] Tchangnwa Nya F.; Ejuh G. W.; Ndjaka J. M. B.; Mater. Lett. 202, 89 (2017).

[18] C. Fonkem, G. W. Ejuh, F. Tchangnwa Nya, R. A. Yossa Kamsi, J. M. B. Ndjaka, J. Iran. Chem. Soc. (2019).

[19] A. Veved, G. W. Ejuh, and G. W. Ejuh, Chinese J. Phys. (2019).

[20] G. W. Ejuh, F. Tchangnwa Nya, N. Djongyang, and J. M. B. Ndjaka, Opt. Quantum Electron. 50, 1 (2018).

[21] D. Freude, «Chapter: Radiation, » Journal of Spectroscopy, 1-21, (2006).

[22] A. Spott, A. Jaroń-Becker, and A. Becker, Phys. Rev. A - At. Mol. Opt. Phys. 90, 1 (2014).

[23] G. W. Ejuh, S. Nouemo, F. Tchangnwa Nya, J. M. Ndjaka, J. Iran. Chem. Soc. 135, 20392048 (2016).

[24] G.W. Ejuh, F. Tchangnwa Nya, M.T. Ottou Abe, F.F. Jean-Baptiste, J.M.B. Ndjaka, Opt. Quantum Electron. 49, 382 (2017).

[25] S. Sakthivel, T. Alagesan, S. Muthu, C. S. Abraham, and E. Geetha, J. of Molecular Structure 1156, 645-656 (2017).

[26] C. D. D. Mveme , F. Tchangnwa Nya, G. W. Ejuh, R. A. Y. Kamsi, J.;.B. Ndjaka Opt. Quantum Electron. 52, 1 (2020).

[27] G. W. Ejuh, F. Tchangnwa Nya, N. Djongyang, and J. M. B. Ndjaka, SN Appl. Sci. 2, 1 (2020).

[28] J. B. F. Fankam, G. W. Ejuh, F. T. Nya, and J. M. B. Ndjaka, Chinese J. Phys. (2020).

[29] M. J. Frisch et al., "Gaussian 16, Revision A.03," Gaussian, Inc., Wallingford CT., 2016

[30] A.D. Becke, J. Chem. Phys. 98, 5648-5652 (1993).

[31] C. Lee, W. Yang, R.G. Parr, Phys. Rev. B 37, 785-789 (1998).

[32] T. Yanai, D. P. Tew, and N. C. Handy, Chem. Phys. Lett. 393, 51 (2004). 
[33] A. Alparone, Chem. Phys. Lett. 536 88-92 (2013)

[34] T. Yanai, R.J. Harrison, N.C. Handy, Mol. Phys. $103413-424$ (2005).

[35] M.J.G. Peach, T. Helgaker, P. Sałek, T.W. Keal, O.B. Lutnæs, D.J. Tozer, N.C. Handy, Phys. Chem. Chem. Phys. 8 558-562 (2006)

[36] R. Kobayashi and R. D. Amos, Chem. Phys. Lett. 420, 106 (2006).

[37] D. Jacquemin, E.A. Perpète, M. Medved, G. Scalmani, M.J. Frisch, R. Kobayashi, C. Adamo, J. Chem. Phys. 126191108 (2007)

[38] A. Limacher, K.V. Mikkelsen, H.P. Lüthi, J. Chem. Phys. 130194114 (2009)

[39] L. Ferrighia, L. Frediania, C. Cappelli, P. Sałekc, H. Ågren, T. Helgakerd, K. Ruuda, Chem. Phys. Lett. 425 (2006) 267-272

[40] Y. Tadjouteu Assatse, G. W. Ejuh, F. Tchoffo, and J. M. B. Ndjaka, Chinese J. Phys. 58, 253 (2019).

[41] N. Kosar, K. Shehzadi, K. Ayub, and T. Mahmood, J. Mol. Graph. Model. 97, 107573 (2020).

[42] H. Tahir, N. Kosar, K. Ayub, and T. Mahmood, J. Mol. Liq. 305, 112875 (2020).

[43] A. Lenz, H. Kariis, A. Pohl, P. Persson, and L. Ojamäe, Chem. Phys. 384, 44 (2011).

[44] W. C. Chen, C. L. Liu, C. T. Yen, F. C. Tsai, C. J. Tonzola, N. Olson, and S. A. Jenekhe, Macromolecules 37, 5959 (2004).

[45] E. G. Kim and J. L. Brédas, J. Am. Chem. Soc. 130, 16880 (2008).

[46] J.M. Raimundo, P. Blanchard, P. Frere, N. Mercier, I. Ledoux-Rak, R. Hierle, J. Roncali, Tetrahedron Letters, 42, 1507 (2001)

[47] A. Savva, E. Georgiou, G. Papazoglou, A. Z. Chrusou, K. Kapnisis, and S. A. Choulis, Sol. Energy Mater. Sol. Cells 132, 507 (2015).

[48] C. (John) Zhang, T. M. Higgins, S. H. Park, S. E. O'Brien, D. Long, J. N. Coleman, and V. Nicolosi, Nano Energy 28, 495 (2016).

[49] Y. J. Cheng, S. H. Yang, and C. S. Hsu, Chem. Rev. 109, 5868 (2009).

[50] A. C. Grimsdale, K. L. Chan, R. E. Martin, P. G. Jokisz, and A. B. Holmes, Chem. Rev. 109, 897 (2009).

[51] G. Ren, P. T. Wu, and S. A. Jenekhe, Chem. Mater. 22, 2020 (2010).

[52] Y. Wen and Y. Liu, Adv. Mater. 22, 1331 (2010).

[53] G. Agalya, C. Lv, X. Wang, M. Koyama, M. Kubo, and A. Miyamoto, Appl. Surf. Sci. 244, 195 (2005).

[54] E. M. Girotto, W. A. Gazotti, and M. A. De Paoli, J. Phys. Chem. B 104, 6124 (2000).

[55] C. Kabé, F. Tchangnwa, N. Geh, W. Ejuh, J. M. Ndjaka, J. Mater. Sci. Mater. Electron., no. 0123456789, (2020).

[56] L. Chen, C. Xu, X.-F. Zhang, J. Mol. Struct. (Thoechem) 863 (1-3), 55-59 (2008).

[57] C. L. Pai, C. L. Liu, W. C. Chen, and S. A. Jenekhe, Polymer (Guildf). 47, 699 (2006).

[58] A. Patra, Y. H. Wijsboom, S. S. Zade, M. Li,Y. Sheynin, G. Leitus, M. Bendikov, J. Am. Chem. Soc. 130, 6734-6736 (2008)

[59] A. Mirsakiyeva, H. W. Hugosson, X. Crispin, and A. Delin, J. Electron.Mater. , 1-5 (2016)

[60] A. Shalabi, S. A. Aal, M. Assem, Nano Energy 1, 608-623 (2012).

[61] A.Mirsakiyeva, H. W. Hugosson, M. Linares, and A. Delin, J. Chem. Phys. 147, (2017). 
[62] K.E. Aasmundtveit, E.J. Samuelsent, L.A.A. Pettersson, O. Inganäs, T. Johansson and R. Feidenhans'l, Synthetic Metals 101 561-564 (1999)

[63] A. R. Chaudhry, R. Ahmed, A. Irfan, M. Mohamad, S. Muhammad, B. U1 Haq, A. G. AlSehemi, and Y. Al-Douri, J. Mol. Model. 22, (2016).

[64] P. Kaatz, E. A. Donley,D. P. Shelton, J. Chem. Phys. 108849 (1998)

[65] A. Karakas, Y. El Kouari, A. Migalska-Zalas, and B. Sahraoui, Photonics Lett. Pol., 4 (1) 1719 (2012).

[66] E. Ortyl, S. W. Chan, J. M. Nunzi, and S. Kucharski, Opt. Mater. (Amst). 29, 2-3 (2006), 268-272,

[67] C. Andraud, T. Brotin, Garcia, F. Pelle, P. Goldner, B. Bigot, A. Collet, J. Am. Chem. Soc. 116(1994) 2094-2102.

[68] L. Jensen and P. T. Van Duijnen, J. Chem. Phys. 123, (2005).

[69] D. P. Shelton, Phys. Rev. A, 42, 2578 (1990)

[70] H.S. Zhou, A. Mito, D. Kundu, I. Honma., Nonlinear Opt. 13, 3 (1995).

[71] C. Andraud, T. Brotin, Garcia, F. Pelle, P. Goldner, B. Bigot, A. Collet, J. Am., 37 Chem. Soc. 116 2094-2102 (1994). 
Figures

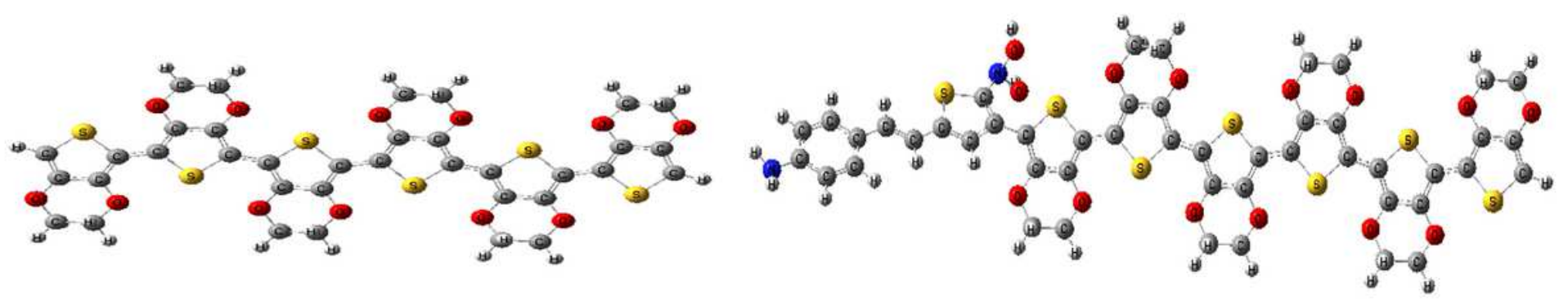

P1) PEDOT

P4) PEDOT/DATVB

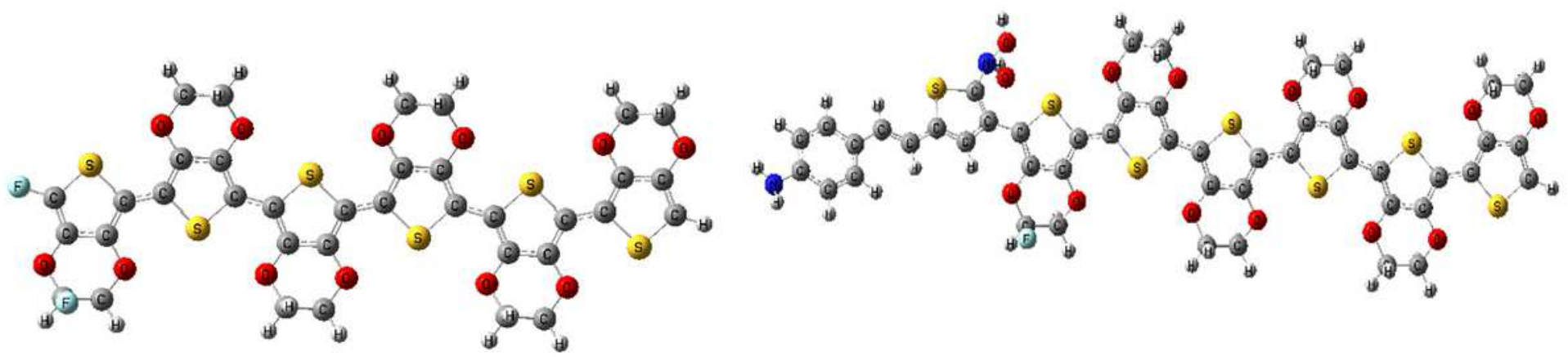

P2) PEDOT-F

P5) PEDOT-F/DATVB

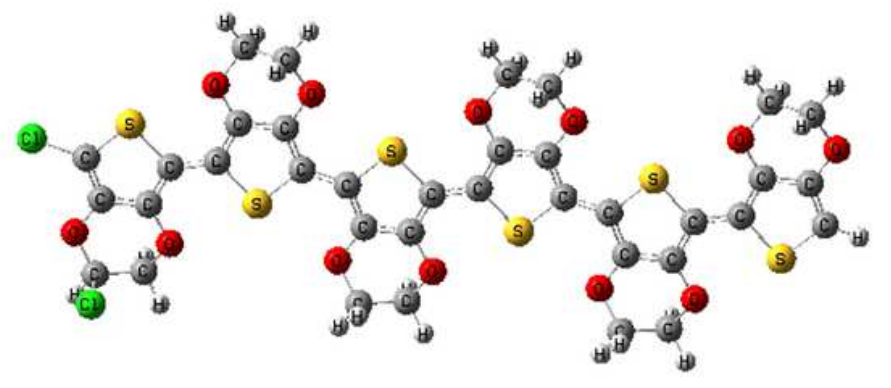

P3) PEDOT-Cl

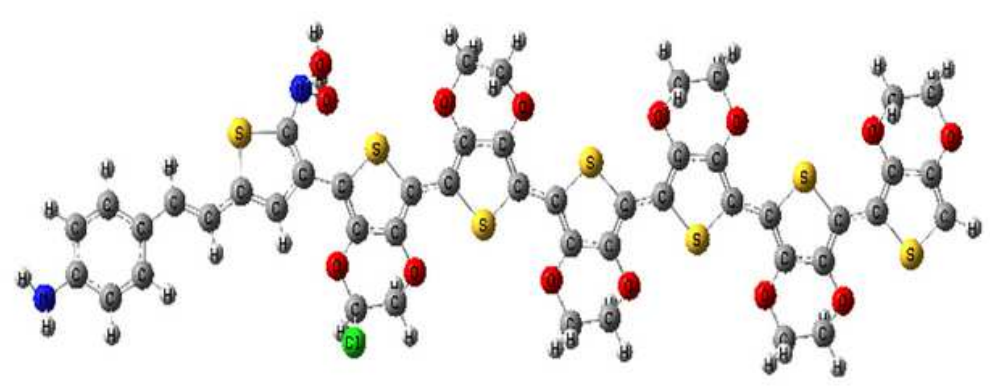

P6) PEDOT-Cl/DATVB

Figure 1

Different optimized molecular systems studied and the complex numbers used (P1 - P6). 

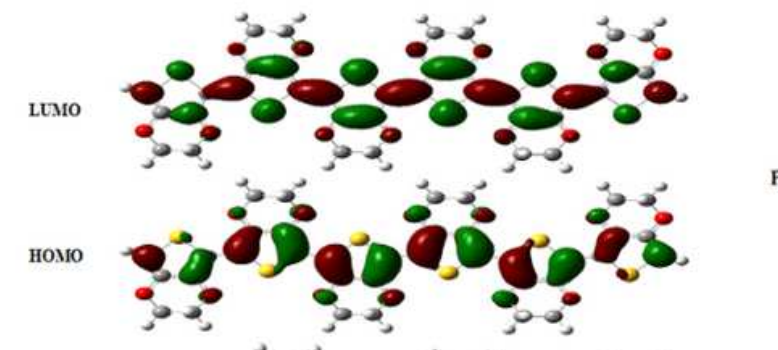

P1
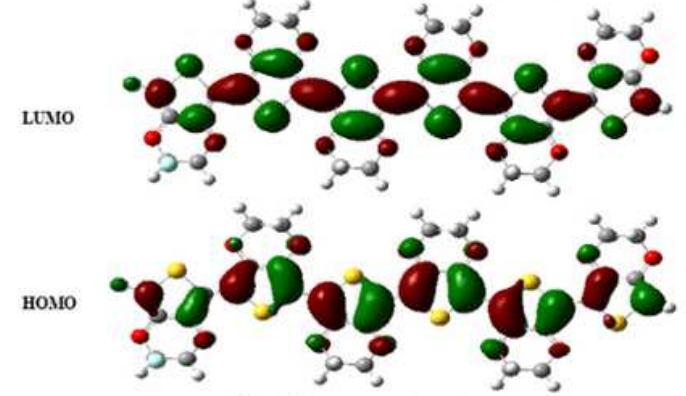

P2
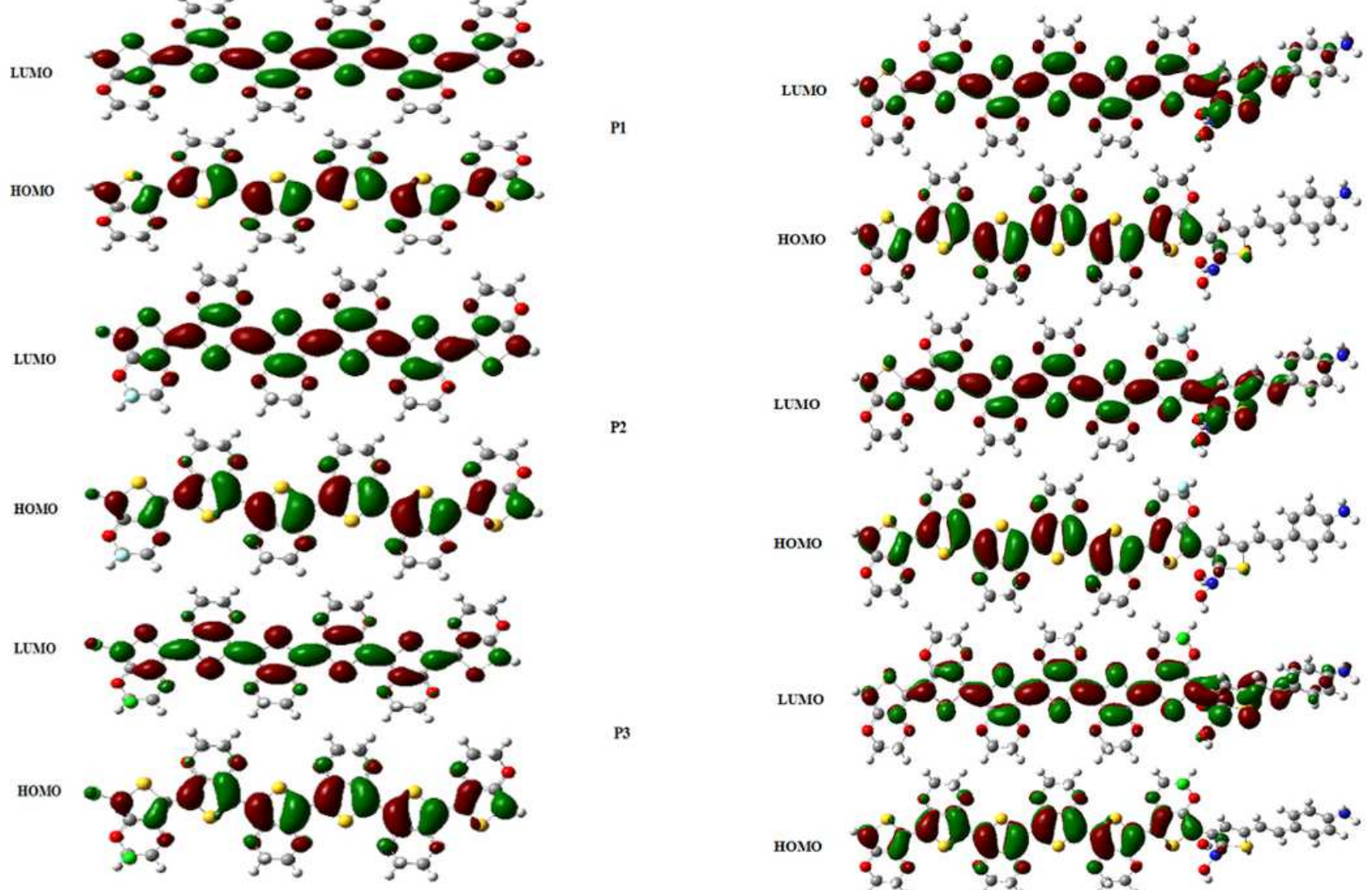

$\mathrm{P}$
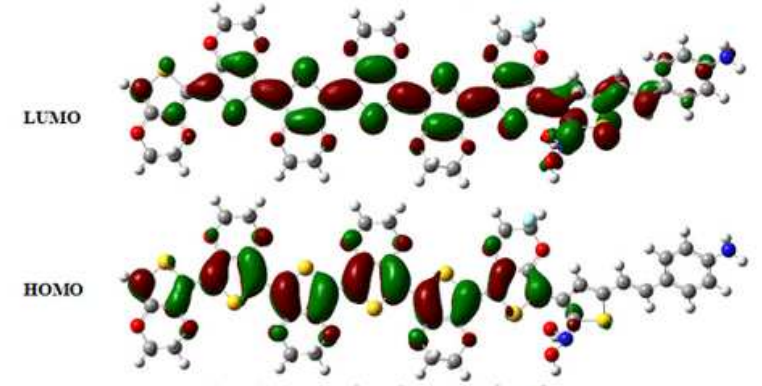

P5
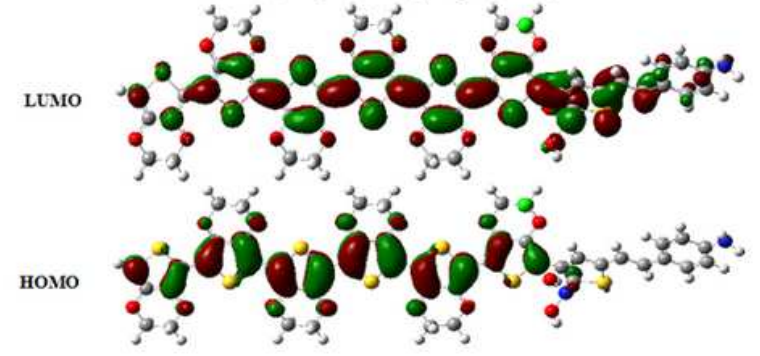

P6

\section{Figure 2}

Diagram of the LUMO and HOMO molecular orbitals of the P1, P2, P3, P4, P5and P6 structures obtained at the B3LYP/6-311++G $(d, p)$ level of theory. 